repair of the annular ligament difficult and hinder rotation of the forearm.

Postoperatively, the elbow is rested in a long-arm plaster slab until the drain is removed. A long-arm hinged brace is then applied; this allows free pronation and supination as well as elbow flexion from 30 to $90^{\circ}$. At the end of the fourth week, full elbow movement is allowed and the brace is taken off at the end of the sixth week.

Illustrative cases. A 13 year-old boy sustained the injury shown in Figure 2. Closed reduction failed, so open reduction and internal fixation was performed by the method described (Fig. 3). At three months he had full range of movement in the elbow and forearm, and radiographs at six months showed a well preserved epiphysis in the radial head.

Case 2. A 23-year-old member of the Hong Kong national fencing squad sustained a type II fracture of the radial neck and a transverse fracture of the radial head. The radial neck fracture was fixed as described, but $2.7 \mathrm{~mm}$ screws were needed.

The radial head fracture was fixed with screws at the same time. After routine postoperative treatment he regained full movement and at the end of three months was able to compete in the Olympic selection match.

No benefits in any form have been received or will be received from a commercial party related directly or indirectly to the subject of this article.

K. S. Leung, FRCS Ed, Lecture

P. Y. T. Tse, FRACS, FRCS Ed, FRCS(Glas), Senior Registrar Department of Orthopaedic and Traumatic Surgery, Prince of Wales Hospital, Shatin, Hong Kong.

Correspondence to Mr. K. S. Leung.

(C) 1989 British Editorial Society of Bone and Joint Surgery $0301-620 X / 89 / 2 \mathrm{R} 96 \$ 2.00$

J Bone Joint Surg [Br] 1989;71-B:326-7.
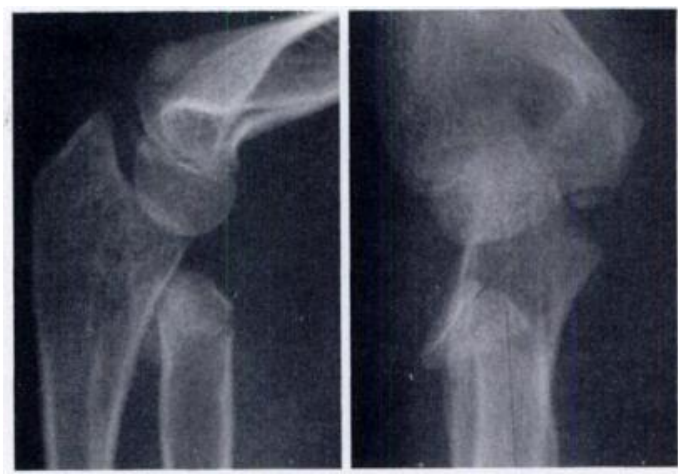

Fig. 2

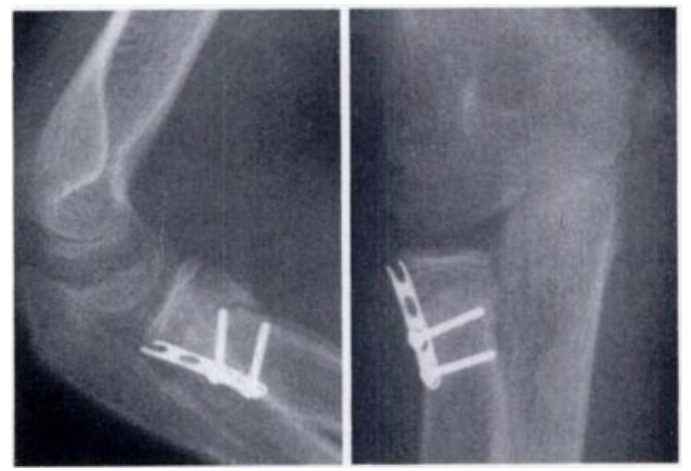

Fig. 3

\section{REFERENCES}

Jones ERL, Esah M. Displaced fractures of the neck of the radius in children. J Bone Joint Surg [Br] 1971 ;53-B:429-39.

O'Brien PI. Injuries involving the proximal radial epiphysis. Clin Orthop 1965;41:51-8.

Ogden JA. Skeletal injury in the child. Philadelphia: Lea \& Febiger, 1982.

Ruedi Th, von Hochstetter AHC, Schlumpf R. Surgical approaches for internal fixation. Springer-Verlag, 1984.

\title{
THE MANAGEMENT OF KNEE FLEXION CONTRACTURES IN HAEMOPHILIA: BRIEF REPORT
}

\author{
I. W. NELSON, R. M. ATKINS, A. L. ALLEN
}

Repeated intra-articular haemorrhages, as seen in the severe haemophiliac, may result in joint contractures. Reversed dynamic slings (Stein and Dickson 1975) are effective in correcting flexion contractures of the knee, but require admission to hospital and close supervision. We describe the use of Flowtron (Medicross Ltd, Eastleigh), an intermittent compression system, in their treatment.

Patients and methods. Between January 1985 and July 1987, 13 haemophiliac patients were admitted to the Nuffield Orthopaedic Centre and underwent treatment of knee flexion contractures with the Flowtron apparatus (Fig. 1). The Flowtron garment is placed on the leg,

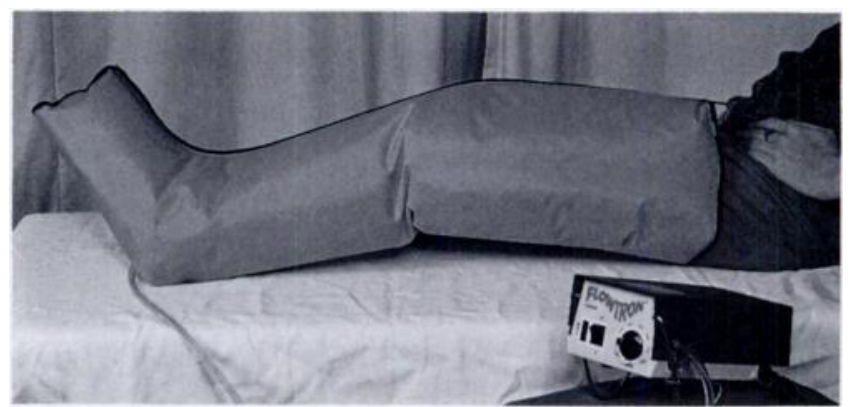

Fig. 1 
inflated to a preset pressure and then deflated over a three-minute cycle by a pneumatic pump. Initial daily treatment is limited to 20 minutes using $30 \mathrm{mmHg}$ pressure. With increased tolerance it may be used up to 60 minutes for two to three times a day at $90 \mathrm{mmHg}$. Between treatment sessions the knee is supported with an Orthoplast splint which is remoulded as necessary.

All the patients suffered from severe haemophilia (less than $5 \%$ factor level) and factor replacement was not routinely administered. The initial and final fixed flexion deformity and the range of flexion were assessed with a goniometer. The figures are expressed as the mean plus or minus one standard error of the mean, and statistical analysis has been performed using paired Student's $t$-test.

Results. The mean flexion contracture before the

I. W. Nelson, FRCS, Clinical Lecturer

R. M. Atkins, MA, FRCS, Clinical Lecturer

A. L. Allen, MCSP, SRP, Senior I Physiotherapist

Nuffield Department of Orthopaedic Surgery, Nuffield Orthopaedic

Centre, Windmill Road, Oxford OX3 7LD, England.

Correspondence to Mr I. W. Nelson

(C) 1989 British Editorial Society of Bone and Joint Surgery 0301-620X/89/2R02 $\$ 2.00$

J Bone Joint Surg [Br] 1989;71-B:327-8. treatment was $26.2 \pm 2.5^{\circ}$ (range 15 to 45 ); after treatment it was $14.2 \pm 2.5^{\circ}$, a significant correction $(p<0.001)$. The range of movement also increased significantly from $56.6 \pm 7.4^{\circ}$ before treatment to $71.5 \pm 7.8^{\circ}$ after $(p=0.005)$. The maximum flexion available was not significantly altered by treatment $\left(82.3 \pm 7.6\right.$ before and $85.8 \pm 6.9^{\circ}$ after treatment $)$. The mean duration of in-patient treatment was 12.2 days. There were no complications and no patient required factor therapy during treatment.

Discussion. Flowtron effectively corrects flexion deformities in the haemophiliac knee. The correction is accompanied by an improvement in the range of movement of the knee which is not merely an alteration in the arc of movement. It is easy to use, suitable for home treatment and the patient can perform quadriceps exercises between sessions.

No benefits in any form have been received or will be received from a commercial party related directly or indirectly to the subject of this article.

\section{REFERENCE}

Stein H, Dickson RA. Brief notes: reversed dynamic slings for knee flexion contractures in the hemophiliac. J Bone Joint Surg [Am] $1975 ; 57-A: 282-3$

\title{
ECTOPIA VESICAE AND CONGENITAL HIP DISLOCATION: BRIEF REPORT
}

\author{
W. G. THOMAS, J. A. WILKINSON
}

Retroversion of the acetabulum predisposes to congenital displacement of the hip. In cases of ectopia vesicae (extroversion of the bladder), the wide diastasis of the pubic symphysis causes acetabular retroversion, thus increasing the likelihood of prenatal hip displacement. Yet the association of the two conditions has not, as far as we know, been previously reported. In the following two cases both conditions were present.

Case 1. In a male infant with ectopia vesicae born by normal delivery, radiography (Fig. 1) revealed a wide diastasis of the symphysis pubis, with apparent hip displacement. Bilateral posterior vertical iliac osteotomies were performed at 10 days with wire cerclage of the pubic bones to aid primary bladder closure, and postoperatively a double spica was applied with the hips in extension. Ten days later the wound broke down and the spica was removed. Nine months later, further clinical and radiographic examination confirmed the hip displacement (Fig. 2) which was treated initially by three weeks vertical traction and abduction splintage. How-

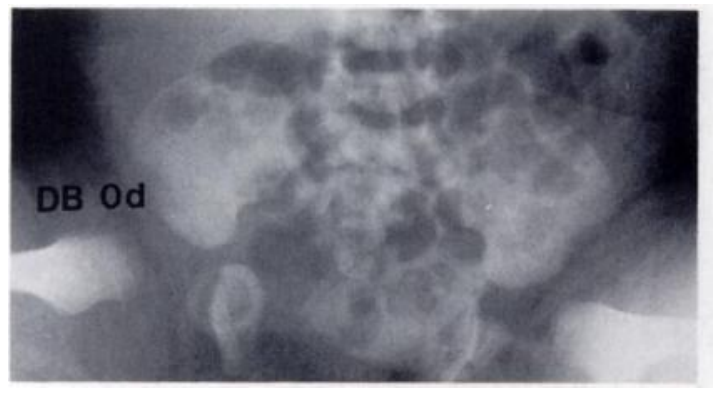

Fig. 1

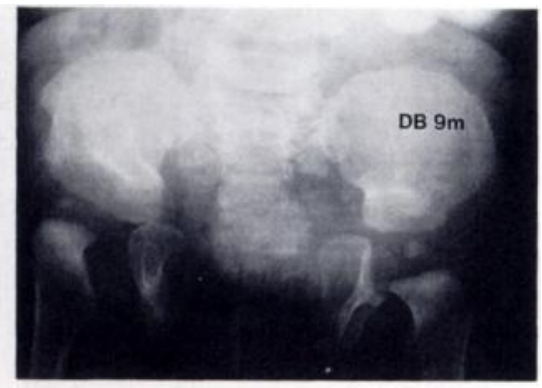

Fig. 2 